\title{
Chapter 13 \\ Integrating is Caring? Or, Caring \\ for Nanotechnology? Being \\ an Integrated Social Scientist
}

\author{
Ana Viseu
}

\subsection{Introduction ${ }^{1}$}

In the Western world, governments and funding bodies increasingly emphasize the need for "responsible research and innovation" practices the integration of the social sciences and humanities within publicly funded research and development (R\&D) initiatives as a means to foster "responsible innovation" (Public Law 108-153; European Commission 2004, 2014). Although the concept "responsible innovation" remains vague, it tends to assume the integration of the social sciences within research and development (R\&D) initiatives, with the goal of maximizing societal benefits while reducing the possibility of negative impacts and public controversy. In the landscape of integration, nanotechnology ${ }^{2}$ has emerged as a primary field site, and the institutional hiring social scientists is one of its instruments. Integrated social scientists are asked to care for nanotechnology research and development by learning how to observe but not disturb. They are assumed to

\footnotetext{
${ }^{1}$ This chapter is a re-reprint of an article published in 2015 (Viseu, 2015a). In preparation for this new publication, I made some minor changes and updated the literature and bibliographic sources. At the end of the chapter, I also include a new section that reflects on the three years that have gone by since the printing of the original article.

${ }^{2}$ In many ways, the term 'nanotechnology' is equally vague and different actors enact it differently. The National Nanotechnology Initiative (NNI) describes it as "science, engineering, and technology conducted at the nanoscale, which is about 1-100 nm" (NNI, n.d). In other words, nanotechnology is encompassing referring to the study, experimentation, tools, and knowledge of matter at the nanoscale.
}

\author{
A. Viseu $(\square)$ \\ Universidade Europeia, Lisbon, Portugal \\ e-mail: ana@anaviseu.org
}
A. Viseu
Centro Interuniversitário de História das Ciências e Tecnologia,
Universidade de Lisboa, Lisbon, Portugal
(C) The Author(s) 2018
E. Subrahmanian et al. (eds.), Engineering a Better Future,
https://doi.org/10.1007/978-3-319-91134-2_13 
broaden the field, while simultaneously guarding its boundaries, shielding it from that which (and those who) stand outside "proper" science. Care emerges as a governance strategy, with social scientists being cast as the main caregivers.

At the core of this chapter is an attempt to engage empirically, conceptually, and affectively with the cares of integration in nanotechnology from the standpoint of the integrated social scientist. To follow integration's journey from policy to embodiment, I draw upon my three-year experience as the in-house social scientist at the Cornell NanoScale Facility (CNF) and the United States' National Nanotechnology Infrastructure Network (NNIN). I argue that, despite integration's potential for creating new modes of collaboration between the social and natural sciences, it is based on traditional and prescriptive arrangements, where disciplinary boundaries, funding provisions and power asymmetries are reified not challenged. Given this socio-material arrangement, integration's potential for opening up science to distinct modes of being, doing and is muted, leading me to conclude that, from the standpoint of those working within Science and Technology Studies (STS), the institutionalized integration of social scientists within R\&D initiatives is designed to fail insofar as social scientists are being called upon to care for nanotechnology by keeping it undisturbed. Moreover, when failure is by design a personal failure - entangled with one's identity and career trajectory - the affective cost of caring for nanotechnology is exceptionally high.

Written in the first person, this article is not meant as a 'confessional tale' (Van Maanen, 1988: 74) that expiates my data generation or fieldwork, nor is it an exercise in reflexivity that conjures me as the holder of a privileged 'epistemic, moral or political virtue' (Lynch, 2000) that my colleagues and subjects did not possess. My goal is to use my three-year experience enacting this policy to write up and analyze the socio-material culture of integration. It is a personal story that puts me at the center of the narrative, and in so doing it is an uncomfortable story, one that I have previously resisted putting into print, even while sharing it at conferences and in lectures. In the course of these events, I heard back from many others (mainly women) who relayed accounts of similar situations, and to their silent voices I add my own. Describing my personal experience is then a means to counter the strategy of individualizing problems in order to turn a blind eye to systemic and collective failures. This is reason enough to write this chapter, but there are others. Examining the current enactments of integration policy is important for Science and Technology Studies (STS) - as well as scholars interested in science and science policy - because integration is going mainstream, slowly becoming a preferred policy tool for the study and management of science and its relations with society; because it effects changes to STS' methods, identity, sustainability, and research sites-helping shape what constitutes a research subject/object, the researcher's position within it, and the kinds of knowledge that can be generated; because it is being done in STS' name ${ }^{3}$; and, because, in its current enactment, integration is of

\footnotetext{
${ }^{3}$ It is hard to know exactly how much money is being allocated to 'societal dimensions' research. For instance, National Nanotechnology Initiative (NNI) claims to have spent US\$182.2 million of
} 
dubious value and is gaining traction without adequate examination. Finally, this analysis is important because conducting it will help to move us towards an analytically skeptical (but not wholly dismissive) perspective on integration, which is key to the development of more suitable collaboration and governance models.

\subsection{Why Care?}

The demand to integrate social sciences issues and concerns and scientific practice and agendas is neither new nor exclusive to nanotechnology. The emergence of demand for integration can be traced back to the 1980s, when a number of trends combined to challenge the established way of publicly funding science. Political demands for greater economic "return-on-investment", public questioning of the direction of technoscientific development, as well as a waning of confidence in the self-regulation of science, all led to a renegotiation of relations between science, the state and citizens (Gibbons 1999; Gibbons et al. 1994; Nowotny et al. 2001; Jasanoff 2005, 2011). Created in 1988, the Human Genome Project's (HGP) "Ethical, Legal, and Societal Implications" (ELSI) program emerged as the first materialization of a model of scientific governance that formally sought to enroll the social sciences and humanities within its midst. It was against the backdrop of the ELSI program, and critiques of its lack of independence, power, and mandate (Wolfe 2000; Fisher 2005; McCain 2002), that nanotechnology policy was brought to life.

The U.S. National Nanotechnology Initiative (NNI) was created in the year 2000 by the Clinton administration to "expedite the discovery, development and deployment of nanoscale science and technology to serve the public good" (NNI, n. d). A total of three years later, the U.S. Congress passed legislation to regulate the NNI, stipulating that all NNI funded research should "insofar as possible, integrate research [and activities] on societal, ethical, and environmental concerns with nanotechnology research and development" (Public Law 108-153, 2003, my emphasis). Albeit pointing to integration as the path forward, the law remains mute on the practical and important issue of how such research will be identified, defined, managed, sponsored, or implemented. Roco and Bainbridge (2001) - two of the architects behind the creation of the NNI-described their rationale for integrating the social sciences and humanities in nano:

The inclusion of social scientists and humanistic scholars, such as philosophers of ethics, in the social process of setting visions for nanotechnology is an important step for the NNI. As scientists or dedicated scholars in their own right, they can respect the professional integrity of nanoscientists and nanotechnologists, while contributing a fresh perspective. Given

its budget on 'education and social dimensions' from 2006 to 2010. While this is a lot of money, Guston (2010) clarifies that it amounts to $2.3 \%$ of the total budget, which is less than the reputed 3-5\% dedicated to Ethical, Legal and Societal Implications (ELSI) during the Human Genome Program. Moreover, Guston argues that most of this funding is for educational endeavors and only between 0.5 and $1 \%$ is dedicated to funding 'societal dimensions' activities. 
appropriate support, they could inform themselves deeply enough about a particular nanotechnology to have a well-grounded evaluation. At the same time, they are professionally trained representatives of the public interest and capable of functioning as communicators between nanotechnologists and the public or government officials. Their input may help maximize the societal benefits of the technology while reducing the possibility of debilitating public controversies. (Roco and Bainbridge 2001: 12)

In other words, social scientists and humanities scholars (narrowly characterized as those studying ethics) are called upon because, being scientists themselves, they are more likely (than the public, one assumes) to understand and be respectful of professional and disciplinary boundaries. To ensure that these boundaries are not crossed, social scientists are summoned to participate in the "social process of setting visions" for nanotechnology, with a few-those who prove themselves willing to being educated in the correct scientific facts-being allowed to go on to provide "well-grounded evaluations" (i.e., based on the aforementioned proper education) of specific nanotechnologies. Finally, social scientists are depicted as communicators and as specialists in the (homogeneous) public, able to contribute to the smooth development and progress of nanotechnology. In sum, integration is imagined less as a means to blur boundaries and extend or open the field of nanotechnology, than as a means to maintain the status quo. Integration reifies a prevailing "turn to ethics" (Jasanoff 2011) that splits the study of technoscience into a domain of values (deemed subjective, extrascientific, and falling within the scope of the social sciences), and a domain of facts (seen as objective, universal, and for experts only). In the integration framework depicted here, social scientists and humanities scholars are entrusted with the job of caring for nanotechnology by learning how to observe, protect, and communicate, without disturbing technical or professional boundaries.

A number of scholars, most prominently feminist science scholars, have long argued that making care visible - both as a practice and an ethos - is key to the study of science and technology (Fox 1980; Fox Keller 1987; Armstrong and Armstrong 2002). Caring, these authors remind us, is not only hard work, it is also work that is often seen as feminine and affect-oriented, work that is devalued and made invisible in the worlds of science and technology. Care is devalued because it is feminized and vice versa. As of late, care has again become front and center in STS studies, namely with Puig de la Bellacasa's (2011) call for science studies scholars to attend to "matters of care" in their engagements with the world-making practices of technoscience (see also, Mol et al. 2010). Matters of care, Puig de la Bellacasa argues, speak of knowledge as doing and intervening, that is, of the ethico-political dimensions of knowledge. They do not replace Latour's (2004) "matters of concern" but rather direct our attention to the affective dimension of our concerns. They do so by evidencing the worries, cares, and responsibilities that are constitutive not only of our engagements, but also of the very things and people we study, and worlds we co-create.

Yet, in the context of integration, care follows a traditional, prescriptive approach emerging as a reductive concept and governance strategy. This richness of contrast, and not the fact that policymakers or scientists use the term, is one reason why "care" is an important heuristic for the study of integration. Examining integration through the lens of care illustrates the multiple definitions, dimensions, 
prescriptions, and affordances of integration and of being an integrated social scientist. Moreover, care, in the words of Haraway (2010), allows me to "stay with the trouble" (see also, Murphy 2015) of integration in nanotechnology, both by troubling and being troubled by it. In sum, examining integration as a kind of care practice and as a matter of care allows me to highlight its often invisible, existential, epistemic, and affective costs, as well as its practices and enactments.

Elsewhere, I have examined the workings of the integration model from the vantage point of nanotechnology practitioners (Viseu and Maguire 2012). Focusing on how practitioners integrate the "social and ethical dimensions" of nanotechnology into their practices, we conclude that current policy has succeeded at normalizing a kind of inclusion of social and ethical issues in the landscape of nanotechnology. This inclusion confers obligations to be fulfilled mostly through outreach and education, as well as personal/moral choices around what (not) to study. At the same time, as some authors have argued, integration has been less than successful at fostering modes of thought, research ethos, or joint relationalities that are inclusive of commitments to social and ethical issues. This chapter extends such arguments by providing evidence of how narrow conceptualizations of the social and the ethical then prompt particular expectations of what an in-house social scientist can, and should, do.

The social sciences have not been passively cast as caretakers in the nanotechnology effort. Instead, they have had a central role in making nanotechnology an issue worthy of care. ${ }^{4}$ Making this point, Nordmann (2007) asserts that the work of maintaining nanotechnology's reality is conducted not only "by advocates and activists, visionary policy makers, [and] scientists when they speak to the public or argue for future funding" but also by "philosophers, ethicists, and social scientists" (Nordmann 2007: 223). It is the latter, he argues, who "have... been recruited to do some of the work that is required to convince a larger audience that "nanotechnology'... [is a] meaningful concept" (Nordmann 2007: 223). The two centers for "nanotechnology in society" created in 2005 attest to this, as do the 308 nanotechnology-related social science articles published between 1998 and 2007 (Shapira et al. 2010), and the "Society for the Study of Nanoscience and Emerging Technologies" created in 2007, to name a few. All these engagements are both products and agents in making nanotechnology into a topic that deserves to be cared for (see also, Karinen and Guston 2010).

STS both mirrors and drives this shift with its growing interest in "engaged" or "interventionist" research. Recall, for instance, the widely cited discussion in the pages of Science, Technology \& Human Values between Webster (2007) and Wynne (2007) on the relationship of STS to science policy, and its possible future as a "serviceable" discipline. STS, one can argue, is often engaged with the worlds it studies (Sismondo 2008); but here I am discussing a particular kind of

\footnotetext{
${ }^{4}$ A colleague who participated in Europe's Deepening Ethical Engagement and Participation with Emerging Nanotechnologies (DEEPEN) told me that one of the project's main conclusions was that it had created a public for nano (João Arriscado Nunes 2011, personal communication; see also, Laurent 2017).
} 
engagement: that which calls for the institutionalized and formal hiring of social scientists in technical facilities. ${ }^{5}$ Described in the literature as "embedded humanists" (Schuubiers and Fisher 2009), "convergence workers" (Gannon 2009), or "engagement agents" (Te Kulve and Rip 2011), integrated scholars are assumed to move closer to the decision-making locus, no longer critical observers but more influential insider agents and/or policy advisors (Webster 2007; Rip 2006, 2009; Stegmaier 2009; Schuurbiers 2011). Yet, reports by in-house social scientists remain mostly ambivalent (Calvert and Martin 2009; Gorman 2011; Hackett and Rhoten 2011; Schuurbiers 2011; Balmer et al. 2012; Doubleday and Viseu 2010; Suchman 2013; Klenk and Meehan 2015; Fitzgerald et al. 2014). And these are the success stories. Experiences of failure, that is, experiences deemed by the embedded social scientist to have failed to create new forms of collaborative scientific practice, are mostly not published, being instead reported at conferences where they are voiced with some shame and received with enthusiasm (Viseu 2012; Aguiton 2012; Thoreau 2012). ${ }^{6}$ The silence surrounding integration attests to its affective cost, one that is compounded by the integrated researcher's position as an insider (embraced as friendly "caretaker"), and an outsider (feared as a "critic"). On this matter, Hackett and Rhoten (2011) conclude that no matter how committed to advancing knowledge an integrated researcher is, after spending a number of years working within an organization, she will attempt to avoid "any possibility" of causing harm. It is not a question, they say, of "going native"; instead it is related to the "liminal status" occupied by these researchers and the conflicts of values inherent to their precarious position as insider/outsider (Hackett and Rhoten 2011: 835; see also, Balmer et al. 2012; Stegmaier 2009).

A few voices have started to speak to the paradoxes of integration. Rabinow and Bennett (2012) examine their integration at the National Science Foundation (NSF) funded "Synthetic Biology Engineering Research Center" (SynBERC), and their failure to "invent a new form of ethical practice" (p. 5) where natural and social scientists would collaborate as equals. The authors depict an environment of deep-seated and untouchable power asymmetries, characterized by resistance both to change and to learning new modes of (collaborative) doing. They portray a politics of funding that made them the only actors exclusively dependent on money from SynBERC, and indicate a confluence between the natural scientists' and the funders' traditional understanding of ELSI as ethics, which functioned to the detriment of the authors' vision (see also, Balmer et al. 2012; Doubleday and Viseu 2010; Viseu and Maguire 2012). Their integration experiment concluded with Rabinow's dismissal, and Rabinow and Bennett's (2012) subsequent realization

\footnotetext{
${ }^{5}$ Two other strategies - the creation of centers dedicated to the study of nanotechnology's societal, ethical and legal implications, and the sponsoring of outreach and educational activities within and by NNI funded technical centers - remain beyond the scope of this chapter.

${ }^{6}$ Anthropologist Christopher Kelty University of California, Los Angeles, (UCLA)) has received so many emails from (mainly female) social scientists concerned about their embeddedness that he has started a database with their names (Christopher Kelty, January 13, 2012, personal communication).
} 
that they "should have known better", that theirs was a Faustian bargain where they "underestimated the existential price to be paid" (Rabinow and Bennett 2012: 173).

Despite its ambivalent track record, integration is increasingly used as a preferred policy tool and as a model for many of STS engagements with technoscience, making it all the more important to examine whether and how it is working. Using care as a heuristic enables me to follow the above cited "existential price" of being integrated, as well as the instructions and articulations that make it pricey. In the next section, I draw upon my experience as the in-house social scientist at a nanofabrication network and facility to address the following questions: What are the parameters of integration? What modes of work and caring are included and excluded? How are the roles of social scientists as care workers defined? What kinds of knowledge are afforded and prevented within this arrangement? What are the costs of being integrated? What constitutes success, for whom and at what cost? My account revolves around the following main issues: the (unacknowledged) different goals of the actors involved; deep asymmetries in power, funding, and personnel numbers; the undervalued status of the social scientist's identity, skills, and knowledge within the initiative; lack of independence; and, finally, affective and epistemic costs of integration. As stated earlier, the details of my experience are intrinsically personal, but they are supported by accounts shared with me by other researchers in similar positions.

\subsection{Caring for Nanotechnology}

Despite integration's novelty as a policy framework, it often comes into being through a top-down request from a funding body, no different from requiring that grant applications include a section on "broader impacts" or "societal value" (see Rabinow and Bennett 2012; Karinen and Guston 2010). Take, for example the case of the 2003 NSF's solicitation for the creation of a network of user facilities, a "National Nanotechnology Infrastructure Network" (NNIN), to support the United States' future infrastructure needs for research and education at the nanoscale. The 16-page solicitation described in loose terms the need to consider the "social and ethical implications" of nanotechnology as "additional review criteria" (NSF 2003:12), requesting that applications "list the issues that will be core concerns... [and] describe plans to facilitate ... cooperation and interchange between scientists and engineers in nanoscience-related fields and social scientists and ethicists studying nanotechnology" (NSF 2003: 9).

One of the networks applying for the NNIN grant was led by the Cornell Nanoscale Facility (CNF), and included among its team Professor Bruce Lewenstein from Cornell's Department of Science \& Technology Studies. The network led by the CNF consisted of 12 sites and one affiliate. Since then it has grown to 14 sites. The CNF's original application included a mandate to "build the intellectual and institutional capacity needed to deal with social and ethical issues as they arise," emphasizing the need for situated studies and specifying that a number 
of social scientists would be embedded within the network so as to facilitate research and foment exchange and discussion (CNF 2003: 31). The CNF-led proposal eventually won the grant, and in the Spring of 2004, as I was completing my $\mathrm{PhD}$, I interviewed for the position of Research Associate on the social and ethical issues in nanotechnology at the CNF/NNIN.

The job interview involved both STS and CNF/NNIN components. The STS part came first and focused on my research and my experience with ethnography. Bruce Lewenstein, Steve Hilgartner (both in the STS department), and I discussed the work that I would do at the CNF/NNIN and spent some time talking about the fantastic opportunity it provided to do ethnographic research on nano, as well as work alongside practitioners on new forms of collaboration. When we were done, Lewenstein escorted me to the newly inaugurated building where the CNF is housed. In contrast to STS's historical building, the CNF's Duffield Hall is new, airy, and stylish, with a high-tech and high-efficiency feel to it (Fig. 13.1). From experience, I know that speaking across disciplines is difficult and as I sat across from the lab manager in his cluttered office, watching him move his leg restlessly, I felt increasingly nervous. When, a few minutes later, the CNF/NNIN's Director ${ }^{7}$ arrived, the interview started. Instead of a dialogue or intellectual exchange, we engaged in a period of "question and answer" that focused not on my research abilities but on what I would call 'instrumental issues'. For instance, one of the first questions was whether it was too early to study the social and ethical implications of nanotechnology, followed by a request to name these implications. I recall being taken aback by this line of questioning, which left me with the impression that it was not the Director's idea to examine these issues or hire someone like me. There was an implication that nano was both a stable construction (worthy of funding and research) and not an entity at all. Politely, I replied that I did not think this question

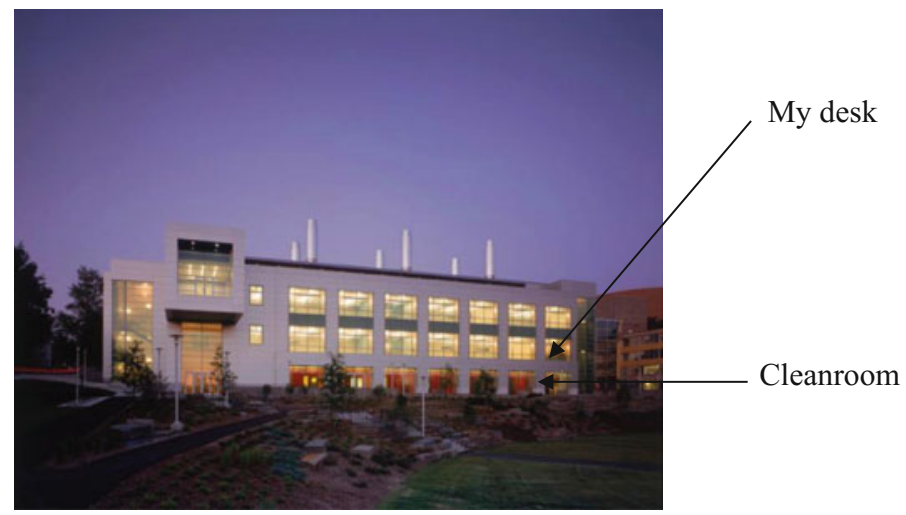

Fig. 13.1 My desk and the cleanroom at Cornell's Duffield Hall where the CNF is located

\footnotetext{
${ }^{7}$ At the time of my hiring, the CNF and the NNIN had the same Director. Later these duties were split.
} 
could, or should, be answered without further studies of nano, its politics, technologies, funding, culture, et cetera. I then gave the standard STS answer that it is important not to speak of implications but think instead of dimensions, so as to highlight the co-production of the social and the technical. I left the CNF certain that I would not get the position. In December, I moved to Cornell.

To be sure, current efforts to integrate issues and concerns of the social sciences and humanities in technoscientific efforts make increased demands on scientists. I could no more expect my interviewers to possess a degree in STS than I could offer them one in nano-engineering. In this sense, the much maligned "deficit model" does work both ways. To state this, however, is to say little. This moment is significant because it points to a problematic reality-making strategy that would be employed for the next three years: a strict, hierarchical interaction with questions that require conventional, immediate, supposedly objective answers about what counts as a social, ethical, or scientific issue.

For the next three years, my job involved responding to and managing the distinct expectations these entities - the CNF, the NNIN, and my STS advisor- - had of what caring for nanotechnology (and for the CNF/NNIN) meant. During this time, I attended the weekly staff meetings, went to staff lunches, celebrations, and picnics, took the CNF's obligatory safety course, led cleanroom visits, learned how to use (some of) the cleanroom equipment, helped organize events, and spoke at events organized by others. In 2007, I helped organize the CNF's 30th anniversary symposium and later conducted oral history interviews with numerous participants, including policymakers, social and natural scientists, and CNF staff members (Viseu and Maguire 2012). Throughout my tenure at the CNF, I learned much and took notes on my new knowledge and observations. The analysis that follows is based on these notes, documents, and experiences.

As I began my job, I thought my integrated status would afford me an opportunity to engage in new forms of collaboration with the CNF community that would be broader than the "ethics" model. I also thought that the STS and CNF communities both acknowledged and took advantage of the many ways in which science is already social and cultural. With some amount of naïveté, I thought this would be a "win-win" situation: I would learn about the practices of doing nano and the CNF's culture, and they would learn more about the social dimensions of their work; together we would produce collaborative practices and knowledge. While I knew that this was not going to be an easy task, I did not anticipate the rigidity of the definitions and expectations of the role that awaited me. The account I am thus able to produce is less about the making of nanotechnology than about the production of the social scientist as the silent and undervalued "care taker" of nanotechnology. My story is not new; it is one of enchantments and disenchantments, it is a story of everyday interactions that are laden with power asymmetries. It serves as a word of caution against interpreting integration-as-governance as a mode that privileges situatedness and collaboration, while overlooking the ways integration reifies boundaries and stereotypes. The intricacies of my three-year experience at the $\mathrm{CNF} / \mathrm{NNIN}$ cannot be done justice here. However, I present four vignettes to illustrate some of the power-laden mundane interactions that defined my role in the 
facility and speak to the question of how to care for nanotechnology. They are exemplars and parables that elucidate the troubles of embeddedness alluded to above.

\subsubsection{Being Integrated or, I Am Outreach}

Having recently celebrated its 35 th anniversary the CNF is, according to a staff member, the oldest end-to-end nanofabrication facility in the United States, standing as an exemplar of nano's legacy and age. The mission of the CNF, then Director George Malliaras told me, is to "proliferate the benefits of nanotechnology and make the facility available to a wide variety of people." In other words, the goal of CNF (and to a large degree that of the NNIN) is not to do research, but to provide the means for users to do so. To that end, the CNF possesses a cleanroom with nanofabrication equipment worth upwards of US \$100 million, employs about 30 full time staff who provide users with assistance and expertise, and runs an operating budget of over US \$5 million.

Shortly after arriving at Cornell University, I made the $\mathrm{CNF}^{8}$ my home base and started to attend the facility's functions. At my first weekly staff meeting, I was introduced as the "ethics coordinator" and was told that I would be given a few minutes toward the end of the meeting to describe my work. As I scanned the room, I counted 25 bodies and gladly noted that six were women (myself included), which was, I thought, not a bad ratio for a technical enterprise. Halfway through the meeting, the lab manager announced, "ok, the administrative staff can leave" and with that four women stood up and headed toward the door. The women who stayed behind fulfilled "typical" female roles: I did "ethics", and my female colleague did "biology". The question of gender in science has long been a topic of exploration by feminists (Fox Keller 1987; Hubbard 1988) and here I found myself implicated in the embodied replication of traditional assumptions regarding gender, divisions of labor, and implicit hierarchical relations between the social and the natural sciences (Barry et al. 2008). The insistence on (wrongly) identifying my expertise and role in the facility as an ethicist added to my discomfort, as it was consistent with what Jasanoff (2011) characterizes as the "turn to ethics [as a] new mode of public reasoning" (p. 633). Ethics then further separates (technical) facts from (subjective) values, thus reinforcing expectations about what and how I would contribute; namely, research on the moral (and public) reasoning on the implications of the nanoscale work being done at the facility. I did not recognize it at the time, but together the subordinated, values-oriented gender division contributed to further defining ethical practice as the site of care work and cast me, an untenured

\footnotetext{
${ }^{8}$ As mentioned above, the CNF was then the organizing node of the NNIN. Unless specified, I will use the two interchangeably since in my daily experiences they were one and the same.
} 
female social scientist, as the care-taker. This in turn added to the liminal status of my position and identity within the CNF. As the CNF Director told me,

[The $\mathrm{CNF}$ ] is an effort that is primarily... 95\% of the budget is for infrastructure and running that infrastructure. And the ethics, at least within this side in the NNIN, is a small fraction of it. That's why there's only one of you and not 5 of you. There's only 1 Doug $^{9}$ and not 5 Dougs.

These a asymmetries are built into the structure of integration; they are not accidental. The bulk of the money and power remains with the technical staff. By implication, the marginal and subordinated role attributed to the social sciences is by design as well.

When it was my turn to speak, I briefly described my background and proceeded to explain that I was not an ethicist but a social scientist, and that my goal was to examine the situated practices through which nano is produced and enacted. I explained that this entailed studying the functioning of the $\mathrm{CNF}$ as an institution, as well as collaborating with the individuals who work in it. I stressed that I did not see my role as encompassing normative judgments of nano, nor was I interested in evaluating individual performances. Instead, I wanted to foster new kinds of scientific practices that made explicit room for their social, ethical, and cultural dimensions. No questions? The meeting was adjourned. I recall the conflict I felt when describing the work I wanted to do at the CNF, namely that of studying the workings of the facility. Managing relationships with subjects is never easy (Brettell 1993; Forsythe 2001), and here it was compounded by both the facts that I was on the facility's payroll and that, besides seeing subjects, I also saw future colleagues. Being paid to care complicated my relationship with the field site in ways novel to me, and I anticipated problems in separating identities, roles and importantly, affective entanglements.

As the weeks went by, I found my colleagues to be cordial yet distant, as if they did not know what to make of me. Since I wanted to be able to collaborate with them, as well as conduct ethnographic research, I decided to learn about the processes of nanofabrication. After taking the obligatory safety training course, I asked a colleague to take me into the lab and teach me how to nanofabricate. We spent three nights in the cleanroom working on two projects: nanocantilevers and carbon nanotube "trees". My notes are replete with explanations, schemes, and drawings. I recall one exchange as particularly telling: we were by the scanning electron microscope and I was having trouble understanding how it worked. My colleague touched the table we were leaning against and said, "this table, for instance, has an atomic structure like this" proceeding to draw it on a piece of paper. I remember realizing then that I was being introduced to a new language, and a new way of seeing. My colleague seemed to be experiencing something akin as he continuously probed me on my background, "A philosopher? A sociologist?" Our first night in the lab ended with me providing him an STS reading list at 3:30 in the morning.

\footnotetext{
${ }^{9} \mathrm{He}$ is referring here to Doug Kysar (Law, Cornell) who substituted Bruce Lewenstein (Science and Technology Studies, (STS)) as my direct supervisor when the latter left the initiative in 2006.
} 
The next day I was late to arrive at CNF and, as I walked in, I noticed that peoples' attitude towards me had changed. Everyone smiled (as they always did), but instead of simply nodding to acknowledge my presence, they would say, "I heard you did well in the lab yesterday!" or "I heard you wear your suit well!", complimenting me on my being careful in the lab. That was my first learning experience: I discovered that through the scientists' and engineers' gossip I had established some scientific credentials, making it easier for my colleagues to find common ground when relating to me. Later in the evening, when I joined my colleague in the cleanroom, he had some news. He told me that he had spoken to the CNF/NNIN's Director about my lab incursion, and that the Director was very excited about it and was going to make sure to include it in the CNF's yearly review report as an outreach activity. And that was my second lesson of the day: I discovered that I was outreach. I was part insider, paid staff with all the obligations that this entails, and part outsider - a sympathetic member of the public whose contribution to the facility was less one of expertise than one of willingness to be educated in the proper way to do and think about nanotechnology. Classifying me as "outreach" made me into a recognizable entity that could be managed and evaluated. In significant ways, I was a success story for integration: a measurable indicator, a compliant hybrid actor whose existence both fits and validates the requirements for integration as defined by Roco and Bainbridge (2001). This position was echoed in interviews that I later conducted with nanopractitioners who also saw me, and my existence, as outreach activities (Viseu and Maguire 2012).

\subsubsection{Defining Integration or, $2+2=4$}

In the summer of 2004, Lewenstein and I were prompted by the CNF to participate in the NNIN's "research for undergraduates" program. We proposed a project that would use qualitative methods to produce a video exploring the "social and ethical issues" of nanofabrication at the CNF, and selected an engineering student to work with us. On the first day, as the undergrads trickled into the facility and started to meet one another, the following conversation took place outside my cubicle:

Undergraduate: So, your mentor, is she a real scientist?

My mentee: She is in the humanities...

Undergraduate: Oh, so she doesn't know anything about all of this...

(her emphasis)

Worried that it was the students who might not know much (or anything!) about the social sciences, and since our video was to be shown and discussed by all 81 undergraduates taking part in the nationwide program, Lewenstein and I emailed them all a reading package. The package included two readings: the first, by Lewenstein (2005), argued that what counts as a social issue in nano should be allowed to emerge from research instead of being defined upfront. The second, by 
Vinck (2003), discussed the (fictitious) experience of a student's internship in a European laboratory, showing that doing science is not only about sitting at the lab bench, but also about politics and diplomacy.

The day after sending out the reading package the CNF/NNIN's Director approached me at my cubicle. Since this had never happened before, I was immediately on alert. "I did not like the text you sent the students and neither will they", he said. I asked why and he went on to discuss the dangers of theory. Then he concluded, "It's like in the old days in math class where they taught the language of math instead of teaching [students] that 2 plus 2 equals 4 ." I explained that one of the articles in particular presented students with the example of someone who was in a situation similar to theirs. In doing so, I said, it introduced them to less obvious (social, ethical, cultural, and political) dimensions and requirements of their work. The CNF Director looked unconvinced and replied that he would like to know what the students thought, and that he hoped "we had good survey results" (we were not planning to do a survey). I mumbled an "I'm sorry you feel that way", and with that he turned his back and left. I, in turn, ran anxiously to the phone to explain to Lewenstein what had just happened. Part of the Director's objection might have been based on pedagogy - rather than emphasize theory, he might have preferred an emphasis on empirical advice and examples - this is, after all, in line with his questions at the initial job interview. But my inability to provide a list of issues that would guide scientists in their "social and ethical issues" incursions, thus contributing to separating these issues from technoscientific practice, remained a sore point throughout my stay at the $\mathrm{CNF}$, an implicit critique that helped define me as an underachiever.

In the aftermath of this episode, it became apparent to me that for the CNF/ NNIN's Director, I was adding unnecessary and unwelcome complexity to nanotechnology, when I was expected to take care of that caring work myself. I worried that for him the value of integrating "the social and the ethical" did not include increasing understanding of the dynamics of lab research and innovation, with recognition of science as culture and its interactions with the wider society (see also, Doubleday and Viseu 2010). Instead, integration meant managing a narrow listing of possible risks and consequences, such that if a scientist followed the instructions and ticked off all the boxes, she was "social and ethical" and could go into the lab without having to worry again. To put it differently, the point was not to share the responsibility for the development of a caring science and technology, nor was it to use my knowledge to enrich current practices, but rather to find minimal, nondisruptive ways to sort through social and ethical issues. This was not a job that I could or wanted to do.

Rabinow and Bennett (2012) argue that the lack of open disagreement in integration engagements of social and natural science is problematic because it is through such disagreement that knowledge advances. They say that dissonance is a welcome shift from the indifference that characterized their own integration experience with synthetic biology. I share both their view and their experience. Yet in important ways, their argument evades the issue of power-dissonance is generative when actors are equals. In the example above, disagreement was not an 
opportunity to exchange ideas but a means to shut them off. It was also a display of power that I could not afford to ignore. This episode functioned both as a moment of recognition - an instance when the work I produced mattered enough for someone to notice it - and as a means to discipline me, ensuring that all definitions and asymmetries remained the same. This is not to say that I was powerless. Marginality, as feminist scholars have long recognized (Harding 1993; Hill Collins 1986), presents possibilities for subversion as well as a standpoint for knowledge creation. I made use of my marginal to draft an introduction to our website specifying that the social and ethical issues of nanotechnology are emergent and cannot be itemized a priori. This text remained online for years after I left the CNF/ NNIN. ${ }^{10}$

\subsubsection{Doing Integration or, the Problem with Users and Their Proxies}

Users, I learned through the course of my stay, are both the CNF's raison d'être and a continual source of problems. The facility's users are an "in-between public" more informed and interested in (nano)science than the public-at-large, yet lacking the knowledge and skill to afford them the insider/expert label. To ensure their safety, as well as that of staff, the cleanroom, and the environment, everyone who uses and works at the CNF must abide by the facilities' safety rules and protocols. A 68-page manual detailing them can be found online (Knight Laboratory 2013), and, most importantly, before going into the cleanroom, all new users attend a mandatory one-and-a-half day orientation and safety course, followed by a test. Yet, inevitably, violations to the rules take place and these are discussed at the weekly staff meetings. Not all rule violations are the same, but neither are all users: somemostly those who have been around for a while and have demonstrated their technical and scientific proficiency - are respected as almost-colleagues. Others are seen as safety risks. The vast majority of users are known by name to the staff. Safety discussions are then both formal and personal; they are discussions of rules and of people.

During my stay at the CNF/NNIN, a decision was made to create training videos for some of the tools that populate the cleanroom, as a further mechanism to ensure proper usage and safety compliance, and prevent accidents. At one particular staff meeting, the question being debated was, "what is the best way to make these videos?" A lively discussion took place with talk of procedures to be highlighted, known problems with the tool, and common user difficulties. I listened to the conversation, and after a while, and since I was formally the facility's social and ethical coordinator, I spoke up to point out that we (I used the term "we"

\footnotetext{
${ }^{10} \mathrm{~A}$ modified version can be found here http://www.nnin.org/society-ethics/about-sei/intro-sei (accessed on 5 August 2015).
} 
purposefully) were being remiss about not including a most important actor in our conversation: the users (Oudshoorn and Pinch 2005). In particular, I suggested that we consult with users on the difficulties they encounter with different machines. Giving them an active voice in the process - rather than making them visible only through third persons accounts of their problems - made all the more sense (to me) since they were also the target audience for the videos.

As soon as I was done talking, a silence and almost palpable reproach overtook the room. My colleagues looked at me with disbelief until someone finally broke the silence, saying that he was not sure we would want to do that - "there are so many problems with that," he said - and, without his needing to specify further, everyone else agreed. At this point, the facility's manager said that he was not sure how much we wanted to include users in the process, but that we could, perhaps, talk to those users that are "accommodating." With that, the conversation was over, leaving me as the lone, out-of-tune voice in the room. ${ }^{11}$ Separate and apart from this, contacting those users who are "accommodating," that is, who have already been "mobilised" (Callon 1986), served the double purpose of appearing to take my intervention onboard while missing out on its main point - involving users who are experiencing issues with the equipment, and who may cause safety problems while doing so.

This speaks to built-in problems of the current integration design, namely its asymmetries in numbers and in power. Being the lone, postdoc female social scientist makes it hard or impossible to diversify and transform entrenched ideas, not only about science and its practice, but also about the social sciences and their possible contributions to the production of knowledge (see also Klenk and Meehan 2015). Emphasizing my knowledge and expertise implied furthering the distance between me and my colleagues, making it harder to justify my presence and usefulness to the facility. My identity and role within the CNF, never fully fitting and never independent, became, when actively exercised, even more unstable and precarious. This was especially so when, as the example above shows, my expertise disrupted existing beliefs. In other words, my presence was tolerated and even welcomed, as long as what I said and did remained within the confines of my own practice and did not disturb the facility's technoscientific culture. It was not only that my knowledge was undervalued - that certainly is not uncommon in interdisciplinary ventures-but that asserting it, especially when there was no-one to back me up, made my posture seem defensive and existence more precarious. Asserting my knowledge further drove a wedge between me and those who paid my salary, such that shame-inducing silence became my most attractive option.

\footnotetext{
${ }^{11}$ A similar thing happened when, months later, we were discussing the need to hire a student to help, and I suggested that given the low female-male ratio, we should make an attempt to hire a female since we had an excellent female candidate.
} 


\subsubsection{Managing Integration or, What Counts as Knowledge}

In the summer of 2005, I was asked to speak at the "Short Course on Technology and Characterization at the Nanoscale" that the CNF organizes every year. The course is attended by staff as well as current and prospective users, giving me a good opportunity to address two pervasive assumptions I was encountering in my daily exchanges with colleagues and users, namely that "the social" and culture are not found inside the lab (and thus that my job, as interesting as it might be, remained outside of their expertise and practice), and that the social sciences' contribution to $\mathrm{R} \& \mathrm{D}$ is personal, normative, or moral. I decided to use the knowledge I was acquiring in my day-to-day observations as the basis for my arguments, thinking that this would help create a common ground and thus make it easier for those in attendance to relate to my talk. I carefully chose three topics that pointed to general issues rather than particular persons: controversies over definitions of contamination, negotiations over professional identity, and issues of tool ownership.

The talk seemed to be well received and was followed by a lively, if mostly off-topic, discussion on government funding, ethics and engineering, and why the public was so afraid of nanotechnology. It was thus all the more surprising when at the next staff meeting, the CNF/NNIN Director made some shrewd remarks about my undercover note taking. Announcing that I "was writing this [meeting] down," he mused aloud that he "guessed this was a public meeting" and that everyone had to be careful about what they said when I was in the room. Depicting me as the evaluator who sits in the corner, he evoked the suspicion that I was an outsider interested in judging what was being said and done, collectively or individually, and that I would later make my judgments public. ${ }^{12}$ Since he was the CNF's main authority, and since, despite his obvious dislike he was not telling me to stop, he also made it sound as if he did not have the power to make me stop, thus reinforcing mistrust of my different, and potentially antagonistic, status. If, on one hand, this is not unusual (Latour and Woolgar 1986 [1979]) and could even be understood as an implicit authorization to continue conducting my ethnography, it also displayed a lack of institutional trust and support. It was as if looking inwards at the lab bench, at the very workings of the CNF, summoned me as an embedded adversary looking for troublesome rather than positive disruptions to existing practices.

\footnotetext{
${ }^{12}$ In what ways does this essay make public judgments, and how do I feel about this? Lucy Suchman, as special issue editor [of the journal where this article was originally published], asked me to reflect on this question. Part of the answer, I think, is covered by time, namely the time I waited before finding it 'safe' to write publicly about this, safe for both me (and my career) and for my CNF colleagues. Another part has to do with my essay's goal, which is not to do an exposé of a problematic site but to address the larger, systemic, endemic problems with the integration model. Still, of all that I have written, this text still raises the most questions for me: regarding my responsibility as an STS scholar and my responsibility toward subjects/colleagues, and regarding public evaluations of me and my work.
} 
This adversarial attitude made itself visible again when, in the month prior to my departure for a job at a Canadian university, my request for a copy of the CNF/ NNIN's original NSF proposal was rejected. (I later asked the overseeing NSF program officer for this proposal, and he too said "no".) One could be led to assume that the CNF was displeased with me, or my performance. But this is not the case. When, in the summer of 2007, I announced I would be leaving for a tenure-track job, the CNF's management asked me to stay onboard for another six months. While I cannot know with certainty, these inconsistent actions could perhaps be explained by a fear that when out of bounds I would be unmanageable. Equipped with three years of 'insider' knowledge, I would be a danger, a whistleblower who could harm the CNF/NNIN and nanotechnology.

These instances speak to my lack of power to define what counted as a proper site of care, and as such poses questions regarding the kinds of knowledge that can be produced within and through formal, institutionalized integration. Lab ethnographies, one of the "foundational pillars" of STS (Doing 2008), involve turning one's integrated gaze inwards, a move that, as I have shown, was received with fear and distrust. Separate and apart from this, ethnographies do not lend themselves to easy evaluation. They are open-ended, time consuming and slow to produce results. Even when concluded, they tend to offer few normative or instrumental answers. All this combines to make them poor evaluation metrics in a landscape ruled by the reigning logics of instrumentality and quick return on investment. Funding agencies expect results, often in the shape of "deliverables"; funded entities must oblige if they want their funding renewed, thus leaving little room for alternative or open-ended, qualitative research. Not surprisingly my contribution to the CNF/ NNIN's output metrics was always carefully steered towards the creation of a web portal featuring the NNIN's activities and accomplishments around nanotechnology's "Social and Ethical Issues" (SEI). The portal, I was told, was to feature a nano-SEI reference database that was expected to be comprehensive and up-to-date. I understood the importance of having a web presence, but objected to the database. I argued that other research groups were exclusively dedicated to doing this and that we would, in effect, be duplicating their work with inferior quality. I quickly found out the database was nonnegotiable. As a public interface, the portal served as a measure of outreach; as a tangible infrastructure, it stood as a symbol of the CNF/ NNIN's commitment to the responsible development of nanotechnology. It was always featured as the main item in the review reports written for the NSF's yearly evaluations. In other words, the portal offered itself as a deliverable that could be easily measured and quantified, such that the larger the database, the bigger the commitment. In so doing, it seemed to remove subjectivity from the "social and ethical", transforming it into a quantified, objective effort. In this translation, I came to impersonate the database, since I was the person charged with caring for it, and it came to impersonate me-with its size and health reflecting my performance and professional identity. The database translated my work and knowledge into a visible, understandable, and manageable deliverable, an entity that could be displayed in the review reports and transformed into metrics in ways that qualitative, open-ended, time-consuming, ethnographic research cannot. 


\subsection{Conclusion}

As policymakers in the Western world increasingly embrace concepts of 'responsible research and innovation', integration goes mainstream. Science policy and funding guidelines have come to include calls for integration of the social sciences and humanities in technoscientific research and development projects to maximize societal benefits while minimizing negative impacts and public controversy. Articulating integration as both a kind of care work and as a 'matter of care' (Puig de la Bellacasa 2011) allowed me to evince the workings, premises, and goals of integration as well the associated and often invisible personal, epistemic, and affective costs of this world-making practice.

It could be argued that some of the issues I examine here are long-standing, and that access always comes at a price, often with "formal and informal provisions on what can be done and said" (Hackett and Rhoten 2011). Indeed, some of the details and conclusions drawn here are probably depressingly familiar to anyone who has ever done fieldwork - and particularly lab ethnography. Yet, as I have shown, there are important differences between the kinds of collaborations that can be fostered through traditional ethnographies, where the researcher has the ability to move between belonging to, and being removed from, the research site (Strathern 1999), and the ones that result from institutionalized calls for the integration of social scientists in R\&D facilities, centers and projects. Being positioned within the initiative offers (in theory) the possibility of greater influence, but it also leaves the integrated researcher more vulnerable to pressure, less independent, and less able to produce and enact a science studies based knowledge and identity.

Some of the problems that I experienced are by design systemic and related to the "care" work I was hired to do. Integration works to eclipse difference, yet difference is ever present. It was present in the unsettling feelings and silences that occurred when the expertise I had to contribute was forced to be read as critical, adversarial, or ungrateful to the people with whom I worked and whose feelings and good opinion I cared about. It was present in my status as staff and outreach. It was present in my training as a qualitative scientist and my desire to do ethnographic research. But it was also silenced in everyday activities and yearly evaluation reports, such that we could speak in only one voice. Asymmetries are also built into integration (it is no coincidence that it is the social sciences who are the subject of the integration), but are made invisible in policy documents and STS reports. Asymmetries in funding, in numbers, and in power, together with an overall utilitarian orientation that focuses on "deliverables", consensus, and quantifiable results, work to constrain the ability of integrated social sciences to define and implement goals, questions, methods, or findings. I note that my condition as a young, untenured woman exacerbated the power asymmetries at work. However, far from making my tale less generalizable or less worrisome, thinking with care exposes the need for increased scrutiny of the dynamics at play so as to enhance the effectiveness and livability of this increasingly common role. Within this framework, caring for nanotechnology is another way to reinforce a divide between facts and values. In other words, despite integration's potential for creating new forms of collaboration between the social and natural sciences, its discourses and 
socio-material orderings are based on traditional and prescriptive arrangements, where disciplinary boundaries, funding arrangements and power asymmetries are not challenged but reified such that there is little to no room to re-imagine existing practices. Integration in its current format is problematic and must be reassessed.

Failure and success have, in STS circles, become relative. As Latour's Aramis (1996) shows us, both are in the eye of the beholder. The same can be said of my experience of integration. Certainly, there were successes - some of them described above - and, in some way, the very publication of this chapter is a measure of success (see also, Rabinow and Bennett 2012). Yet, as integration and the in-house social scientist model gain traction, we must question their goals and implementation. If our goal is to work towards the opening of science to other actors, questions, and methods, to foster new collaboration models, and to facilitate shared knowledge, then the institutionalized integration of social scientists within R\&D initiatives is designed to fail because in its current enactment, social scientists are being called upon to care for nanotechnology by keeping it undisturbed, and doing care differently is understood as a threat. Moreover, when failure is by design personal failure - entangled with one's identity and career trajectory - the affective cost of integration is exceptionally high.

The road ahead is as difficult as it is uncertain. We must continue working toward fostering scientific practices that are inclusive of commitments to social and ethical issues. Doing so requires a continued effort to transform current integration policy so as to include and facilitate broader, less utilitarian enactments of the scientific work, social sciences, and (care) work they are slotted to perform. Some "easy" fixes may be insisted upon: integration should accommodate teams of social scientists, rather than one or two individuals; ${ }^{13}$ funding for these teams should not be controlled by, or depend on, the site of integration; the teams must be given the power to define and implement their activities; and, last but not least, evaluation of their activities must be conducted by peers. This is a starting place, yet there is more work to be done. We must insist on the value of complexity, such that results from these collaborations do not need to be presented in one voice, or in one metric-friendly deliverable. We must continue to move away from a framework where collaboration with social scientists is adversarial rather than positive, and where success is equated with consensus. We must continue to work toward an understanding of science that is inclusive of affective, response-able (Haraway 2007), and shared relationships, such that dualisms are replaced by entanglements.

As we work toward this we in the field of STS must also take a closer look at the positions we adopt toward and within the worlds we study and co-construct. Positionality has long been recognized by feminist science scholars such as Hill Collins (1986), Haraway (1988), and Harding (1993) as key to epistemology and knowledge production because all knowledge is locally situated. Positionality is

\footnotetext{
${ }^{13} \mathrm{I}$ am reminded here of Wynne's account of withdrawing from a government program because "acting without STS allies [he] was utterly unable to diversify existing entrenched ideas about innovation and future expectations" (Wynne 2007: 497).
} 
also intimately connected to power and knowledge such that some entities and groups remain central while others are marginalized and neglected, thus limiting or enabling the production of particular kinds of knowledge (Hill Collins 1986; Harding 1993). Reflecting on her years working as an anthropologist at Xerox PARC, Suchman (2013) argues that where researchers are located "is perhaps the critical question" (p. 147) as it speaks to issues of sponsorship (who pays for the research) and accountability (who is responsible for defining the research questions, methodology, conceptual framework, et cetera) that articulate and afford different frames of reference and values. It is naïve, she suggests, to expect the frames of reference of all actors to be the same. As she goes on to illustrate, in the process of negotiation, differences are often obliterated in the interest of speaking in one voice. Thus, she says, in an ironic twist of fate, the more successful a project is, the less room there is for configuration and difference, and the more likely it is that STS knowledge is appropriated (Suchman 2013; see also Wynne 2007; Joly and Kaufmann 2008). Likewise, Rabinow and Bennett (2012) end their account by recommending to others that they find a position that allows them to "remain adjacent" (p. 177) to the initiatives they study. Reflecting on positionality involves, at the very least, speaking aloud of the troubles of integration: the kinds of traditional and prescriptive arrangements that frame and gauge its success, the instrumentalization of social science work it imposes, the differences it eclipses, and its existential, epistemic, and affective costs. In a world of decreased funding for social sciences and humanities, speaking out of tune is both difficult and crucial. It may also involve a return to a position outside of the spotlight of funding bodies and policy agencies.

Ideally, we would see 'stand-alone' funding for the social sciences increased without requirements for integration or subordination to a given topic or big science initiative. But in the current context this seems unlikely. In its absence, and in a position that is likely to be unpopular among STS scholars, I argue that we should push to a return to funding structures that resemble those of the HGP's ELSI program. The ELSI program was part of the HGP (and its funding was subordinated to the HGP's budget) but worked as a granting entity with its own administrative and funding structures. I am not advocating replicating the ELSI model, with its emphasis on after-the-fact impacts, and its enduring (and warranted) lack of independence that precluded questioning of the very project that set it up. Yet, I would like to point out that despite these (and other) handicaps ELSI was key in funding numerous important pieces of critical scholarship (e.g. Kay 2000; Sloan 2000; see also, Lindee 1994). I am not sure the same can be said of nanotechnology, where criticism of funding arrangements, for instance, has been remarkably absent. I am arguing that we build upon (not replicate) the ELSI model's organizational structure and work to ensure that we create granting bodies that have some degree of autonomy and are adequately staffed, funded, and importantly, evaluated. Nonengagement with the world and its subjects is not an option. But we must remain analytically skeptical and find positions where collaboration and the situated knowledge generated within those collaborations is a starting point for critical questions and reassessments. 


\subsection{Afterword}

I end this chapter with an attempt to answer the question that I am invariably asked when presenting the material upon which this chapter is based: given the current integration policy framework, what is the one thing I recommend we do to succeed in our engagements and collaborations?

In the three years since the publication of this article we have witnessed two concurrent and paradoxical developments: on one hand, integration, consolidated into the label of "responsible research and innovation" (RRI), has become firmly rooted as a mainstay of technoscientific policy (see, for instance, de Saille 2015a; Fisher forthcoming; Horizon 2020 nd). On the other hand, there has been an increase in the number of articles that examine the difficult workings of integration as governance (see, for instance, Giordano 2018; Klenk and Meehan 2015; de Saille 2015b; Ribeiro et al. 2017).

Many of the critiques currently being leveled at integration are in line with my argument and past experience, and I will not repeat them here. Recently, however, integration has been studied in its connections to distinct political models and technologies. This is an important argument that deserves attention. In their article, Klenk and Meehan (2015) argue that integration is foremost an "idealization of how scientists 'should work' with the diversity of actors/stakeholders" with the goal of producing "normative knowledge and policy-relevant solutions aimed at societal problems" (p.160). If this formulation sounds familiar it is because it replicates the discourse of Western policymakers and funding bodies. For instance, Horizon 2020 - the European Union's current research and innovation funding programme-describes the rationale for RRI stating,

Responsible Research and Innovation (RRI) implies that societal actors (researchers, citizens, policy makers, business, third sector organisations, etc.) work together during the whole research and innovation process in order to better align both the process and its outcomes with the values, needs and expectations of society. (H2020 n.d)

In other words, in the face of a complex and heterogeneous world, integration is figured as facilitating (instrumental) technoscientific solutions directed at societal problems. Klenk and Meehan (2015) go on to argue that if integration is to blur disciplinary lines then it must address the politics of knowledge. Yet, as I have argued, integration tends to hide the messiness of dissenting voices and of alternative ways of knowing, favoring instead the consensus (see also, Viseu 2015b). Klenk and Meehan (2015) conclude that "the integration imperative conceals the friction, antagonism and power exclusion inherent in knowledge co-production" (p. 161). I would argue that not only do the politics of knowledge production remain invisible-above I described that integration tends to hide the messiness of dissenting voices and alternative ways of knowing, favoring instead consensuswhat is increasingly evident is that integration is by design blind to politics and power. Moreover, as argued by Giordano (2018), "the superficial language of rights and democracy [used in current RRI policy documents] relegitimizes the primacy of scientific discovery to solve societal problems" (p. 401). Thus, in ironic but not 
unexpected ways, integration (and the corollary "responsible research and innovation") may work to place more, not less, authority in a few, expert hands while simultaneously reinforcing the divide between the social and the scientific expert knowledge.

In his book, Laurent (2017) examines the links between nanotechnology and democracy. Taking problematization to mean "the range of ways to tackle a problem" (p.18), Laurent argues that the ways in which nanotechnology is made into a problem speak to how democracy itself is problematized. His comparative analysis shows, for instance, how distinct instruments work to create informed and participating publics and/or deliberating citizens, in Europe and the United States. Importantly, Laurent describes the ways in which French experiments with nanotechnology worked to exclude the most active and participating public: the anti-nano activists. He is not alone in this conclusion. Both Giordano (2018) and de Saille (2015a, 2015b) caution that RRI may, in fact, be working to exclude unruly and critical publics.

Deciding how an issue is framed, what is privileged, who gets to participate and how, who (and what) is excluded - is at the heart of politics. Creating room for disagreement and alternative ways of caring and knowing is essential for and in a democracy. Yet, my experience, as described above, is that in its current enactments integration does not facilitate disagreement and may in fact hinder it (see also, Giordiano 2018; de Saille 2015b; Ribeiro et al. 2017). To facilitate collaboration and engagement in technoscientific development and innovation it is not enough to integrate so as to be representative, it is also necessary to attend to configurations of power, to funding and evaluation mechanisms, and vitally, to the generative role of dissent.

It is with the generative value of dissent that I end my story. When reflecting upon their integration experience, Rabinow and Bennett (2012) advise other social scientists engaged in integration experiments to "speak the truth frankly" (p. 179); Fitzgerald et al. (2014) provide the contrary advice: they suggest that collaborators make use of "equivocal speech", which they describe as an approach that is "attentive to the things that are better left unsaid, to the feelings that are as well off not articulated and to the senses of awkwardness and ignorance that probably will not help anything if openly acknowledged." (p. 716). I would like to suggest a third alternative: that we practice a politics of "collaborative dissent", that is, a mode of working-together that acknowledges distinct motivations and goals; that is welcoming of complexity and does not attempt to speak in unison; that does not equate a plurality of views with failure, but with achievement; that knows that dissent can be generative and enriching — and in fact, crucial — to a democratic society. Insisting on dissent and complexity will not eclipse power differences, but it may ameliorate them enough to facilitate the creation of distinct ways to care and produce knowledges.

Acknowledgements I would like to acknowledge support from the National Nanotechnology Infrastructure Network, where I worked from 2004 to 2007. I would also like to thank the anonymous reviewers who were generous, enthusiastic, and invaluable in helping me develop my thinking.

Funding This work was supported by the National Science Foundation under grant no. ECS-0335765. 


\section{References}

Aguiton, S. (2012). Etre embarquée das une competition de biologie synthétique. Paper delivered at the 'Sciences Sociales Embarquées' Colloque International, organized by CETCOPRA (Université Paris 1) \& CSI (Mines ParisTech), Paris, France, January 13 \& 14, 2012.

Armstrong, P., \& Armstrong, H. (2002) Thinking it through: Women, work and caring in the New Millenium. Canadian Woman Studies/Les Cahiers De La Femme, 21/22(4/2), 44-50.

Balmer, A., Bulpin, K., Calvert, J., Kearnes, M., Mackenzie, A., Marris, C., et al. (2012). Towards a manifesto for experimental collaborations between social and natural scientists. Available at: http://experimentalcollaborations.wordpress.com. Accessed November 29, 2012.

Barry, A., Born, G., \& Weszkalnys, G. (2008). Logics of interdisciplinarity. Economy and Society, 31(1), 20-29.

Brettell, C. B. (Ed.). (1993). When they read what we write: The politics of ethnography. Westport, Connecticut \& London: Bergin \& Garvey.

Callon, M. (1986). Some elements of a sociology of translation: Domestication of the scallops and the fishermen of St. Brieuc Bay. In J. Law (Ed.), Power, action and belief: A new sociology of knowledge? Sociological Review Monograph (Vol. 32, pp. 196-233). London, UK: Routledge \& Kegan Paul.

Calvert, J., \& Martin, P. (2009). The role of social scientists in synthetic biology. Science and Society Series on Convergence Research. EMBO (European Molecular Biology Organization) Reports, 10(13), 201-204.

Cornell Nanofabrication Facility (CNF) (2003) National Nanotechnology Infrastructure Network Proposal: Submitted to NSF in response to NSF 03-519.

de Saille, S. (2015a). Innovating innovation policy: the emergence of 'Responsible Research and Innovation'. Journal of Responsible Innovation, 2(2), 152-168.

de Saille, S. (2015b). Dis-inviting the Unruly Public. Science as Culture, 24(1): 99-107.

Doing, P. (2008). Give me a laboratory and I will raise a discipline: the past, present, and future politics of laboratory studies in STS. In E. J. Hackett, O. Amsterdamska, M. Lynch \& J. Wajcman (Eds.), The Handbook of Science and Technology Studies. Cambridge, MA: MIT Press, 279-298.

Doubleday, R., \& Viseu, A. (2010). Questioning interdisciplinarity: What roles for laboratory based social science? In K. Kjolberg \& F. Wickson (Eds.), Nano meets macro: Social perspectives on nano sciences and technologies (pp. 51-75). New Jersey: Pan Stanford Publishing.

European Commission. (2004). Towards a European strategy on nanotechnology. Brussels: European Commission. Available at: ftp://ftp.cordis.europa.eu/pub/nanotechnology/docs/ nano_com_en.pdf. Accessed March 30, 2009.

European Commission. (2014). Horizon 2020 in Brief: the EU Framework Programme for Research \& Innovation. Luxembourg: Publications Office of the European Union. Available at: http://ec.europa.eu/programmes/horizon2020/en/news/horizon-2020-brief-euframeworkprogramme-research-innovation (accessed 12 March 2015).

Fisher, E. (2005). Lessons learned from Ethical, Legal and Social Implications program (ELSI): Planning societal implications research for the national nanotechnology program. Technology in Society, 27, 321-328.

Fisher, E. (forthcoming). "Enhancing Micro-foundations of Responsible Innovation: Integration of Social Sciences and Humanities with Research and Innovation Practices." In: R Von Schomberg (ed) Handbook of Responsible Innovation. Cheltenham, UK: Edward Elgar.

Fitzgerald, D., Littlefield, M., Knudsen, KJ., Tonks, J. \& Dietz, MJ. (2014). Ambivalence, equivocation and the politics of experimental knowledge: A transdisciplinary neuroscience encounter. Social Studies of Science, 44(5): 701-721.

Forsythe, D. (2001). Studying those who study us: An anthropologist in the world of artificial intelligence. Writing Science Series. Stanford, CA: Stanford University Press. 
Fox, B. (Ed.). (1980). Hidden in the household: Women's domestic labour under capitalism. Toronto: The Women's Press.

Fox Keller, E. (1987). The gender/science system: Or, is sex to gender as nature is to science? Hypatia, 2(3), 37-49 (Special Edition on 'Feminism \& Science 1').

Gannon, F. (2009). Convergence (Editorial). EMBO (European Molecular Biology Organization) Reports, 10(2), 103.

Gibbons, M. (1999). Science's new social contract with society. Nature, 402, C81-C84.

Gibbons, M., Limoges, C., Nowotny, H., Schwartzman, S., Scott, P., \& Trow, M. (1994). The new production of knowledge: The dynamics of science and research in contemporary societies. London: Sage.

Gorman, M. (2011). Doing science, technology and society in the National Science Foundation. Science and Engineering Ethics, 17(4), 839-849.

Guston, D. (2010, May). Societal dimensions research in the national nanotechnology initiative (CSPO Report \#10-02). Arizona State University. Consortium for Science, Policy \& Outcomes. [Online]. Available at: http://www.cspo.org/library/title/?action=getfile\&file= 291\&section=lib. Accessed November 17, 2010.

Hackett, E. J., \& Rhoten, D. R. (2011). Engaged, embedded, enjoined: Science and technology studies in the National Science Foundation. Science and Engineering Ethics, 17(4), 823-838.

Haraway, D. (1988). Situated knowledges: The science question in feminism and the privilege of partial perspective. Feminist Studies, 14(3), 575-599.

Haraway, D. (2007) When Species Meet. Minneapolis, MN: University of Minnesota Press.

Haraway, D. (2010). When species meet: Staying with the trouble. Environment and Planning D: Society and Space, 28(1), 53-55.

Harding, S. (1993). Rethinking standpoint epistemology: What is "Strong Objectivity"? In L. Alcoff \& E. Potter (Eds.), Feminist epistemologies (pp. 49-82). London: Routledge.

Hill Collins, P. (1986). Learning from the outsider within: The sociological significance of black feminist thought. Social Problems, 33(6), S14-S32.

Horizon (2020). (nd). Responsible Research and Innovation. Available at: https://ec.europa.eu/ programmes/horizon2020/en/h2020-section/responsible-research-innovation (accessed 12 June 2018)

Hubbard, R. (1988, Spring). Science, facts and feminism. Hypatia, 3(1), 5-17 (Special Edition on 'Feminism and Science 2').

Jasanoff, S. (2005). Designs on nature: Science and democracy in Europe and the United States. Princeton: Princeton University Press.

Jasanoff, S. (2011). Constitutional moments in governing science and technology. Science and Engineering Ethics, 17(4), 620-638.

Joly, P.-B., \& Kaufmann, A. (2008). Lost in translation? The need for 'Upstream Engagement' with nanotechnology on trial. Science as Culture, 17(3), 1-23.

Karinen, R., \& Guston, D. H. (2010). Toward anticipatory governance: The experience with nanotechnology. In M. Kaiser, M. Kurath, S. Maasen, \& C. Rehmann-Sutter (Eds.), Governing future technologies: Nanotechnology and the rise of an assessment regime (pp. 217-232). The Netherlands: Springer.

Kay, LE. (2000). Who Wrote the Book of Life? A History of the Genetic Code. Stanford, CA: Stanford University Press.

Klenk, N. \& Meehan, K. (2015). Climate change and transdisciplinary science: Problematizing the integration imperative. Environmental Science \& Policy, 54: 160-167.

Knight Laboratory. (2013). Cornell NanoScale Science and Technology Facility (CNF) Laboratory usage \& safety manual. Available at: http://www.cnf.cornell.edu/doc/ CNF_Lab_Manual_10th_edition.pdf. Accessed April 10, 2013.

Latour, B. (1996). Aramis or the love of technology. Cambridge, MA: Harvard University Press.

Latour, B. (2004). Why has critique run out of steam? From matters of fact to matters of concern. Journal of Critical Inquiry, 30(2), 225-248.

Latour, B., \& Woolgar, S. 1986 [1979]. Laboratory life: The social construction of scientific facts. Beverly Hills, London: Sage. 
Laurent, B. (2017). Democratic experiments: problematizing nanotechnology and democracy in Europe and the United States. Cambridge, MA: MIT Press.

Lewenstein, B. (2005). What counts as a 'Social and Ethical Issue in Nanotechnology?' HYLEInternational Journal for Philosophy of Chemistry, 11(1), 5-18 (Special edition on 'Nanotech Challenges' Part 2. Jointly published with Techne).

Lindee, S. (1994). The ELSI hypothesis. Isis 85(2): 293-296.

Lynch, M. (2000). Against reflexivity as an academic virtue and source of privileged knowledge. Theory, Culture \& Society, 17, 26-54.

McCain, L. (2002). Informing technology policy decisions: The US human genome project's ethical, legal, and social implications programs as a critical case. Technology in Society, 24, $111-132$.

Mol, A., Moser, I., \& Pols, J. (Eds.). (2010). Care in practice: On tinkering in clinics, homes and farms. Bielefeld: Verlag.

Murphy, M. (2015). Unsettling care: Troubling transnational itineraries of affect in feminist health practices. Social Studies of Science, 45(5): 717-737.

National Nanotechnology Initiative (NNI) (n.d). NNI vision, goals and objectives. Available at: http://www.nano.gov/about-nni/what/vision-goals. Accessed November 10, 2005.

Nordmann, A. (2007). Knots and strands: An argument for productive disillusionment. Journal of Medicine and Philosophy, 32(3), 217-236.

Nowotny, H., Scott, P., \& Gibbons, M. (2001). Re-thinking Science: Knowledge and the public in an age of uncertainty. Cambridge: Polity Press.

National Science Foundation (NSF). (2003). National Nanotechnology Infrastructure Network (NNIN) program solicitation (Program Solicitation NSF 03-519). Available at: http://www.nsf. gov/pubs/2003/nsf03519/nsf03519.pdf. Accessed June 18, 2006.

Oudshoorn, N., \& Pinch, T. (Eds.). (2005). How users matter: The co-construction of users and technology. Cambridge, MA: MIT Press.

Public Law 108-153. (2003). 21 st century nanotechnology research and development act. 108th Congress. Available at: http://frwebgate.access.gpo.gov/cgi-bin/getdoc.cgi?dbname=108 cong_public_laws\&docid=f:publ153.108.pdf. Accessed June 12, 2008.

Puig de la Bellacasa, M. (2011). Matters of care in technoscience: Assembling neglected things. Social Studies of Science 41(1): 85-106.

Rabinow, P., \& Bennett, G. (2012). Designing human practices: An experiment with synthetic biology. Chicago, IL: The University of Chicago Press.

Ribeiro BE, Smith RDJ and Millar K (2017). A Mobilising Concept? Unpacking Academic Representations of Responsible Research and Innovation. Science and Engineering Ethics, 23 (1): 81-103.

Rip, A. (2006). Folk theories of nanotechnologists. Science as Culture, 15(4), 349-365.

Rip, A. (2009). Futures of ELSA. Science \& Society Series on Convergence Research. EMBO (European Molecular Biology Organization) Reports, 10(7), 666-670.

Roco, M., \& Bainbridge, W. S (Eds.). (2001) Societal implications of nanoscience and nanotechnology, Final Report, National Science Foundation Workshop, September 28-29, 2000. Arlington, VA: NSF. Available at: http://www.wtec.org/loyola/nano/NSET.Societal. Implications/nanosi.pdf. Accessed February 07, 2004.

Schuurbiers, D. (2011). What happens in the lab does not stay in the lab: Applying midstream modulation to enhance critical reflection in the laboratory. Science and Engineering Ethics, 17 (4), 769-788.

Schuubiers, D., \& Fisher, E. (2009). Lab-scale intervention. Science \& Society Series on Convergence Research. EMBO (European Molecular Biology Organization) Reports, 10(5), 424-427.

Shapira, P., Youtie, J., \& Porter, A. L. (2010). The emergence of social science research on nanotechnology. Scientometrics, 85(2), 595-611.

Sismondo, S. (2008). Science and technology studies and an engaged program. In E. Hackett, O. Amsterdamska, M. Lynch, \& J. Wajcman (Eds.), The handbook of science and technology studies (pp. 13-31). Cambridge, MA: MIT Press. 
Sloan, PR. (ed.) (2000). Controlling Our Destinies: Historical, Philosophical, Ethical, and Theological Perspectives on the Human Genome Project. Notre Dame, IN: University of Notre Dame Press.

Stegmaier, P. (2009). The rock ' $n$ ' roll of knowledge co-production. Science \& Society Series on Convergence Research. EMBO (European Molecular Biology Organization) Reports, 10(2), 114-119.

Strathern, M. (1999). Property, substance and effect. Anthropological essays on persons and things. London: Athlone Press.

Suchman, L. (2013). Consuming anthropology. In A. Barry \& G. Born (Eds.), Interdisciplinarity: Reconfigurations of the social and natural sciences (pp. 141-160). London: Routledge.

T Kulve, H., \& Rip, A. (2011). Constructing productive engagement: Pre-engagement tools for emerging technologies. Science and Engineering Ethics, 17(4), 699-714.

Thoreau, F. (2012). Being enrolled and being engaged back. Paper delivered at the 'Sciences Sociales Embarquées' Colloque International, organized by CETCOPRA (Université Paris 1) \& CSI (Mines ParisTech), Paris, France, January 13 \& 14, 2012.

Van Maanen, J. (1988). Tales of the field: On writing ethnography. Chicago and London: The University of Chicago Press.

Vinck, D. (Ed.). (2003). Everyday engineering: An ethnography of design and innovation. Cambridge, MA: MIT Press.

Viseu, A. (2012). Integrating the social: Being a social scientist in a nanotechnology laboratory. Paper delivered at the 'Sciences Sociales Embarquées' Colloque International, organized by CETCOPRA (Université Paris 1) \& CSI (Mines ParisTech), Paris, France, January 13 \& 14, 2012.

Viseu, A., \& Maguire, H. (2012). Integrating and enacting 'social and ethical issues' in nanotechnology practices. NanoEthics, 6, 195-209.

Viseu, A. (2015a). Caring for nanotechnology? Being an integrated social scientist. Special Issue on 'The Politics of Care in Technoscience'. Social Studies of Science, 45(5): 642-664.

Viseu, A. (2015b). Integration of social science into research is crucial (World View). Nature, 525 (7569): 291.

Webster, A. (2007). Crossing boundaries social science in the policy room. Science, Technology and Human Values, 32(4), 458-479.

Wolfe, A. (2000). Federal policy making for biotechnology, executive branch, ELSI. In T. H. Murray \& M. J. Mehlman (Eds.), Encyclopedia of ethical, legal and policy issues in biotechnology (Vol. 1, pp. 234-240). New York: Wiley.

Wynne, B. (2007). Dazzled by the mirage of influence? STS-SSK in multivalent registers of relevance. Science, Technology and Human Values, 32(4), 491-503.

Open Access This chapter is licensed under the terms of the Creative Commons Attribution 4.0 International License (http://creativecommons.org/licenses/by/4.0/), which permits use, sharing, adaptation, distribution and reproduction in any medium or format, as long as you give appropriate credit to the original author(s) and the source, provide a link to the Creative Commons license and indicate if changes were made.

The images or other third party material in this chapter are included in the chapter's Creative Commons license, unless indicated otherwise in a credit line to the material. If material is not included in the chapter's Creative Commons license and your intended use is not permitted by statutory regulation or exceeds the permitted use, you will need to obtain permission directly from the copyright holder.

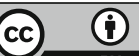

